\title{
Penentuan Kondisi Optimum Proses Ekstraksi Uranium dan Torium dari Terak II Timah dengan Metode Pelindian Asam Sulfat dan Solvent Extraction Trioctylamine (TOA)
}

\section{Determination of Optimal Conditions for Extracting Uranium and Thorium from Tin Slag II with a Sulfuric Acid Leaching and Trioctylamine (TOA) Solvent Extraction Method}

\author{
Mutia Anggraini ${ }^{1 *}$, Fuad Wafa' Nawawi ${ }^{2}$, Kurnia Setiawan Widana ${ }^{1}$ \\ ${ }^{1}$ Pusat Teknologi Bahan Galian Nuklir-BATAN, Jl. Lebak Bulus Raya No. 9, Ps. Jumat, Jakarta, Indonesia, 12440 \\ ${ }^{2}$ Program Studi Teknik Metalurgi dan Material, UI, Kukusan, Beji, Kota Depok, Jawa Barat, Indonesia, 16425 \\ *E-mail: mutiaa@batan.go.id
}

Naskah diterima: 23 April 2019, direvisi: 14 Mei 2019, disetujui: 28 Mei 2019

DOI: $\underline{10.17146 / \text { eksplorium.2019.40.1.5378 }}$

\begin{abstract}
ABSTRAK
Terak II timah merupakan produk hasil samping dari peleburan timah tahap kedua. Terak II timah ini mengandung unsur bernilai ekonomi tinggi berupa unsur radioaktif (uranium dan torium) dan logam tanah jarang (rare earth element). Unsur-unsur tersebut dapat dimanfaatkan apabila telah terpisah satu dengan lainnya. Proses pemisahan unsur radioaktif dan unsur logam tanah jarang telah dilakukan dengan metode pelindian asam sulfat. Hasil proses ini adalah endapan yang mengandung logam tanah jarang dan filtrat yang mengandung unsur radioaktif berupa uranium dan torium sulfat. Penelitian terkait pemisahan uranium dan torium hasil pengolahan terak II timah hanya sedikit dipublikasikan. Paper ini bertujuan untuk mengetahui efektifitas proses pemisahan uranium dan torium dengan metode solvent extraction menggunakan trioctylamine (TOA). Proses solvent extraction dilakukan dengan memvariasikan konsentrasi TOA yang digunakan, perbandingan fase aqueous dan fase organik (A/O) dan variasi waktu ekstraksi. Pada penelitian ini diperoleh kondisi optimum proses yaitu konsentrasi TOA 4\%, perbandingan A/O 1 : 1, dan waktu pencampuran aqueous dan organik selama 2 menit. Pada kondisi ini uranium dan torium yang terekstrak masing-masing sebanyak $67 \%$ dan $0,84 \%$.
\end{abstract}

Kata kunci: terak timah, solvent extraction, uranium, torium, trioctylamine (TOA)

\begin{abstract}
Tin slag II is a by-product of the second stage of tin smelting. The tin slag II contains high economic value elements in the form of radioactive elements (uranium and thorium) and rare earth elements. These elements can be utilized if they are separated from each other. The process of separating radioactive elements and rare earth elements has been carried out by leaching sulfuric acid method. The results of this process are residue containing rare earth elements and filtrates containing radioactive elements in the form of uranium and thorium sulfate. Research related to the separation of uranium and thorium sulfate in tin slag processing is only slightly published. This paper aims to determine the effectiveness of the uranium and thorium separating process by the solvent extraction method using trioctylamine (TOA). The solvent extraction process is carried out by varying the concentration of TOA used, comparison of the aqueous and organic phase (A/O) and variations in extraction time. In this study, the optimum conditions for the process were obtained at 4\% of TOA concentration, $1: 1$ of A/O ratio, and mixing time of aqueous and organic phase for 2 minutes. In this condition, uranium and thorium which extracted were $67 \%$ and $0.84 \%$ respectively.
\end{abstract}

Key words: tin slag, solvent extraction, uranium, thorium, trioctylamine (TOA) 


\section{PENDAHULUAN}

Kepulauan Bangka Belitung merupakan penghasil timah terbesar di Indonesia. PT Timah (Persero) Tbk. merupakan perusahaan pengolah timah terbesar di Indonesia. Disamping memproduksi timah, perusahaan yang mengelola timah juga menghasilkan produk samping berupa terak timah (tin slag) [1]. Timah dalam bentuk mineral kasiterit diolah dengan cara pemisahan fisik dan proses peleburan (smelting) [2].

Pemisahan fisik bertujuan untuk meningkatkan kadar timah dengan memisahkannya dari mineral pengotor seperti monasit, zirkon, ilmenit, dan xenotime. Kadar timah yang telah meningkat dari 5-6\% Sn menjadi $72 \%$ Sn dilebur pada suhu tinggi kemudian dimurnikan sehingga dihasilkan logam timah dengan kadar tinggi [3].

Ada dua tahapan pada proses peleburan yaitu peleburan tahap I dan II. Peleburan tahap I menghasilkan timah kasar dan terak timah I, sedangkan peleburan tahap II menghasilkan hardhead (paduan FeSn) dan terak II timah [3]. Terak II timah belum dimanfaatkan seoptimal mungkin [1] dan masih disimpan pada stock pile. Meskipun sebagai limbah proses pengolahan timah, terak II timah masih mengandung unsur bernilai ekonomis tinggi. Hasil karakterisasi XRF terhadap terak II timah menunjukkan adanya oksida logam tanah jarang (LTJ) dan unsur radioaktif berupa uranium dan torium.

Logam tanah jarang terdiri dari 15 unsur lantanida yaitu $\mathrm{La}, \mathrm{Ce}, \mathrm{Pr}, \mathrm{Nd}, \mathrm{Pm}, \mathrm{Sm}, \mathrm{Eu}$, Gd, Tb, Dy, Ho, Er, Tm, Yb, dan Lu serta ditambah Sc dan Y [4]. Scandium (Sc) dan ytrium (Y) digolongkan sebagai logam tanah jarang karena memiliki sifat kimia yang sama dengan unsur dalam golongan lantanida [5]. Logam tanah jarang dibagi menjadi dua kelompok yaitu light rare earth elements
(LREE) dan heavy rare earth elements (HREE). Kelompok LREE meliputi unsur La, Ce, Pr, Nd, Sm, dan Eu. Sedangkan HREE meliputi unsur Gd, Tb, Dy, Ho, Er, Tm, Yb, dan $\mathrm{Lu}$ [6]. Unsur radioaktif yang terkandung dalam terak II timah berupa uranium dan torium dengan kadar 619 ppm uranium dan 5.300 ppm torium [7].

Logam tanah jarang dan unsur radioaktif dapat dimanfaatkan apabila telah terpisah satu dengan yang lainnya. Logam tanah jarang dapat dimanfaatkan pada berbagai industri yang memanfaatkan material maju seperti unsur Nd yang dimanfaatkan sebagai bahan baku magnet permanen [8], unsur Tb, Dy, dan Er sebagai bahan sensor [9]. Sedangkan unsur radiokatif berupa uranium dan torium dapat dimanfaatkan sebagai bahan bakar untuk reaktor nuklir [10]. Pemanfaatan unsur radioaktif dan unsur logam tanah jarang dari terak timah tidak hanya menjadi keuntungan secara ekonomi, namun juga menjadi solusi bagi kelestarian lingkungan. Oleh sebab itu diperlukan proses yang tepat untuk memisahkan unsur-unsur berharga yang terkandung dalam terak II timah.

Penelitian ini membahas mengenai kondisi optimum proses pemisahan logam tanah jarang dan unsur radioaktif sehingga dapat meningkatkan kadar uranium dan torium melalui metode pelindian dengan asam sulfat $\left(\mathrm{H}_{2} \mathrm{SO}_{4}\right)$ [7]. Selain itu, penelitian ini juga bertujuan untuk mengetahui efektivitas proses pemisahan uranium dan torium melalui metode ekstraksi dengan trioctylamin (TOA).

\section{TEORI}

Terak adalah gabungan dari beberapa senyawa oksida dan silikat. Terak pada umumnya mengandung sejumlah logam berharga yang dapat digunakan sebagai 
sumber logam kedua [11]. Terak timah yang ada di Indonesia memiliki struktur semu (Gambar 1). Struktur semu merupakan struktur kristalin yang memiliki susunan logam berikatan dengan elemen lain dalam suatu mineral [12].

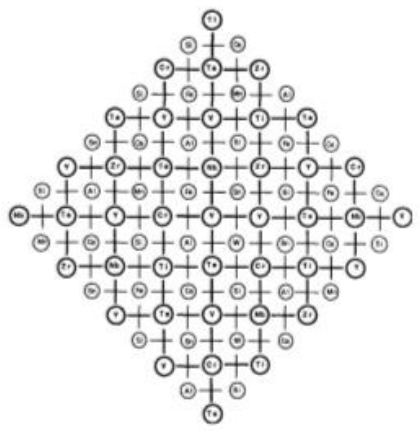

Gambar 1. Struktur terak timah Indonesia [12].

Di dalam terak timah masih banyak kandungan logam lain selain timah seperti zirkon, mangan, besi, aluminium, titanium, silikon, LTJ, tantalum, niobium, dan unsur radioaktif. Logam tersebut dapat diekstrak kembali dari terak timah sehingga dapat meningkatkan nilai ekonomi terak timah. Salah satu metode yang digunakan untuk meningkatkan nilai ekonomi adalah metode ekstraksi kandungan logam yang terkandung dalam terak timah.

Hidrometalurgi merupakan suatu proses ekstraksi yang berisi serangkaian proses yang saling berkaitan untuk memulihkan (recovery) dan memurnikan suatu elemen dalam suatu larutan aqueous. Terdapat beberapa teknik hidrometalurgi, namun teknik yang umum digunakan untuk ekstraksi hidrometalurgi torium dan uranium adalah teknik solvent extraction atau liquid-liquid extraction. Solvent extraction merupakan suatu metode untuk memisahkan suatu senyawa berdasarkan kelarutannya dalam suatu sistem [13]. Secara umum, metode solvent extraction dilakukan dengan mencampurkan larutan yang mengandung ion logam dengan fase organik sehingga mencapai keadaan setimbang (equilibrium), kemudian didiamkan hingga terbentuk dua fase yang terpisah berdasarkan berat jenis dari kedua fase tersebut [14]. Fase organik yang mengandung ekstraktan akan memiliki nilai specific gravity yang lebih kecil dibandingkan dengan fase aqueous, sehingga fase organik akan berada di atas fase aqueous dalam sistem tersebut. Fenomena ekstraksi logam pada larutan dapat diamati berdasarkan derajat ekstraksi logam.

Derajat ekstraksi logam metode solvent extraction dapat digambarkan dengan rasio distribusi (distribution of ratio), faktor separasi (separation factor), dan persen ekstraksi (percentage of extraction). Rasio distribusi $\left(\mathrm{K}_{\mathrm{d}}\right)$ merupakan perbandingan konsentrasi dari zat yang terdapat dalam fase organik ([A]org) terhadap konsentrasi zat dalam fase aqueous ([A]aq) pada keadaan setimbang. Rasio distribusi dijelaskan melalui persamaaan berikut [15]:

$$
K d=\frac{[A] \text { org }}{[A] a q}
$$

Persen ekstraksi atau extraction factor biasanya digunakan untuk aplikasi industri yang merujuk pada jumlah logam yang terekstrak pada suatu proses. Persen ekstraksi (\% E) dijelaskan melalui persamaan berikut [15]:

$$
\% E=100 \times \frac{D}{(1+D)}
$$

Nilai D adalah rasio distribusi. Ketika nilai D $=1$, maka hal tersebut menandakan bahwa sistem terdistribusi menjadi dua fase.

Faktor separasi mengindikasikan kemampuan suatu sistem untuk memisahkan dua zat yang berbeda. Faktor separasi dijelaskan dengan persamaan:

$$
\beta_{B}^{A}=\frac{D_{A}}{D_{B}}
$$


Nilai $\mathrm{D}_{\mathrm{A}}$ merupakan rasio distribusi dari zat $\mathrm{A}$, dan $\mathrm{D}_{\mathrm{B}}$ merupakan rasio distribusi dari zat B [15].

\section{METODOLOGI}

Penelitian ini dilakukan melalui beberapa tahap yaitu proses roasting, milling dan sieving, leaching, serta solvent extraction. Analisis unsur dilakukan dengan metode analisis menggunakan Spektrofotometer UVVis 2600 Shimadzu untuk penentuan kadar uranium dan ICP-OES Optima 8300 DVS/N.078S1305275 untuk penentuan kadar torium. Penentuan kadar uranium dan torium berdasarkan intensitas emisi pada panjang gelombang yang khas dari masing-masing unsur yang dianalisis [16].

Proses roasting dilakukan dengan mencampurkan terak II timah dan $\mathrm{NaOH}$, kemudian dipanggang pada suhu $700{ }^{\circ} \mathrm{C}$ [17]. Hasil proses roasting berupa endapan (frit). Frit yang terbentuk kemudian digerus (milling) dan diayak (sieving), selanjutnya digunakan sebagai umpan proses leaching. Frit yang telah halus direaksikan dengan $\mathrm{H}_{2} \mathrm{SO}_{4}$ pada suhu $80{ }^{\circ} \mathrm{C}$ [17] kemudian dilakukan filtrasi. Filtrat yang dihasilkan merupakan umpan pada proses solvent extraction.

Proses solvent extraction dilakukan dengan memvariasikan konsentrasi TOA yang digunakan yaitu $2 \%, 3 \%, 4 \%, 5 \%$, dan $6 \%$ dalam kerosene dan isodecanol $2 \%$, pebandingan fase aqueous dan fase organik (A/O) dengan variasi 1/1, 1/2, dan 1/3; dan variasi waktu ekstraksi yaitu 2, 5, 10, 15, dan 20 menit.

\section{HASIL DAN PEMBAHASAN}

Roasting dengan $\mathrm{NaOH}$ bertujuan untuk menghilangkan lapisan oksida silika pada terak II timah. Lapisan oksida silika dalam terak II timah dapat mengganggu proses ekstraksi unsur yang diinginkan. Oksida silika mengikat oksida-oksida lain sehingga oksida tersebut sulit dipisahkan. Oksida lain lain tersebut di antaranya adalah oksida besi, uranium, torium, dan logam tanah jarang [7].

Mekanisme penghilangan oksida silika dari terak II timah dengan roasting $\mathrm{NaOH}$ yaitu dengan cara mereaksikan $\mathrm{SiO}_{2}$ dan ion natrium $\left(\mathrm{Na}^{+}\right)$dari $\mathrm{NaOH}$ sehingga didapatkan senyawa $\mathrm{Na}_{2} \mathrm{SiO}_{3}$. Di sisi lain, oksida-oksida lain seperti oksida torium, uranium dan tanah jarang, akan bereaksi dengan ion hidroksida $\left(\mathrm{OH}^{-}\right)$dari $\mathrm{NaOH}$ sehingga didapatkan senyawa torium hidroksida, uranium hidroksida, dan LTJ hidroksida.

Reaksi yang terjadi pada proses roasting terak II timah dengan $\mathrm{NaOH}$ yaitu [7]:

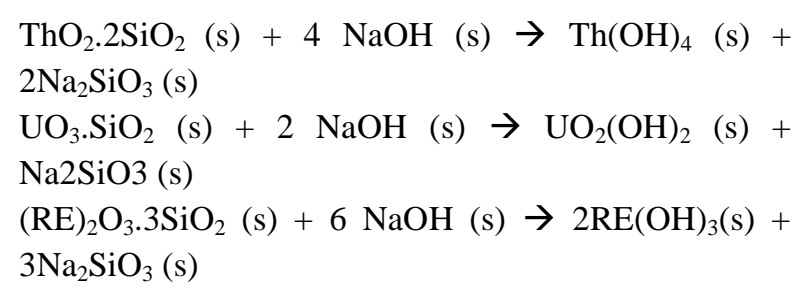

Endapan hasil proses roasting dengan $\mathrm{NaOH}$ kemudian dicuci dengan air. Endapan yang dihasilkan setelah proses pencucian ini berwarna kecoklatan dan memiliki pH 11. Fungsi dari pencucian endapan ini adalah untuk menghilangkan natrium silikat $\left(\mathrm{Na}_{2} \mathrm{SiO}_{3}\right)$ yang terbentuk pada proses roasting. Karena sifatnya yang mudah larut dalam air, Natrium silikat $\left(\mathrm{Na}_{2} \mathrm{SiO}_{3}\right)$ dapat dihilangkan dengan cara melarutkannya menggunakan air sehingga didapatkan endapan hasil roasting bebas silika dan mengandung unsur (U, Th, RE) $\mathrm{OH}$ [7].

Endapan hasil roasting yang mengandung uranium, torium, dan logam tanah jarang selanjutnya direaksikan dengan asam sulfat untuk memisahkan unsur 
radioaktif (U, Th) dan unsur logam tanah jarang. Reaksi asam sulfat dengan logam tanah jarang menghasilkan endapan REE sulfat. Unsur logam tanah jarang dapat mengendap pada kondisi alkali sulfat. Keberadaan sisa ion $\mathrm{Na}^{+}$yang tidak bereaksi dengan $\mathrm{SiO}_{2}$ dalam residu hasil fusi dan penambahan asam sulfat menciptakan kondisi alkali sulfat sehingga terbentuk residu $\mathrm{NaREE}\left(\mathrm{SO}_{4}\right)^{2}$ [7]

$$
\mathrm{Na}^{+}+\mathrm{REE}^{3+}+2 \mathrm{SO}_{4}{ }^{2-} \rightarrow \operatorname{NaREE}\left(\mathrm{SO}_{4}\right)_{2(\mathrm{~s})}
$$

Selain residu $\operatorname{NaREE}\left(\mathrm{SO}_{4}\right)_{2}$, reaksi endapan hasil roasting dengan asam sulfat juga menghasilkan filtrat yang mengandung uranium dan torium sulfat [7]. Hal ini berarti unsur radioaktif dan unsur logam tanah jarang dapat dipisahkan.

Filtrat yang mengandung uranium dan torium sulfat selanjutnya akan digunakan sebagai umpan pada proses solvent extraction. Proses ini bertujuan untuk memisahkan uranium dan torium dalam filtrat sulfat. Proses pemisahan unsur Th dan U dilakukan dengan menggunakan konsentrat trioctylamine (TOA). Konsentrat TOA dengan rumus molekul $\left[\mathrm{CH}_{3}\left(\mathrm{CH}_{2}\right)_{7}\right] 3 \mathrm{~N}$ merupakan salah satu tertiary amine dan berjenis ekstraktan basa. Tertiary amine dapat digunakan untuk memisahkan $\mathrm{U}$ dan Th dari medium sulfat dan klorida tanpa mengalami masalah degradasi amina [18].

Mekanisme pemisahan $\mathrm{U}$ dan $\mathrm{Th}$ didasarkan pada pengikatan secara selektif $U$ dari suatu medium larutan oleh ekstraktan. Pada proses ini larutan yang mengandung $\mathrm{U}$ dan Th dicampurkan dengan ekstraktan organik dan dilakukan pengadukan. Sistem kemudian akan membentuk dua fase larutan yang berbeda, yaitu fase aqueous dan fase organik. Uranium akan berpindah dari larutan aqueous menuju ke larutan organik akibat adanya reaksi dengan ekstraktan organik (TOA). Reaksi yang terjadi antara U dan TOA yaitu sebagai berikut [18]:

$3\left(\mathrm{R}_{2} \mathrm{NH}_{2}\right) 2 \mathrm{SO}_{4}+\mathrm{UO}_{2}\left(\mathrm{SO}_{4}\right)_{2}^{2-} \rightarrow\left(\mathrm{R}_{2} \mathrm{NH}_{2}\right) 6 \mathrm{UO}_{2}\left(\mathrm{SO}_{4}\right)_{4}+$ $\mathrm{SO}_{4}{ }^{2-}$

Reaksi tersebut bergantung pada konsentrasi TOA yang ditambahkan, perbandingan jumlah $\mathrm{A} / \mathrm{O}$, dan waktu proses.

Pengaruh konsentrasi TOA yang ditambahkan diamati berdasarkan jumlah uranium dan torium yang berada pada larutan organik dibandingkan dengan kadar uranium dan torium sebelum dilakukan proses ekstraksi. Persen jumlah uranium dan torium yang terekstrak pada larutan organik dapat dilihat pada Gambar 2.

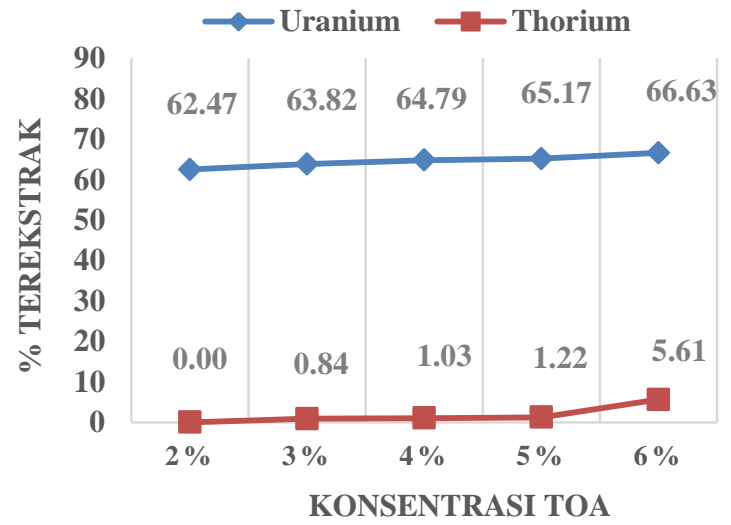

Gambar 2. Pengaruh konsentrasi TOA terhadap kadar uranium dan torium.

Jumlah uranium yang terekstrak pada berbagai variasi konsentrasi TOA yang ditambahkan memiliki nilai yang hampir sama yaitu berkisar antara 62-66\%. Semakin besar konsentrasi TOA maka uranium yang terekstrak juga semakin besar, akan tetapi jumlah torium yang terekstrak juga besar. Hal ini disebabkan karena uranium maupun torium terlarut dalam asam sulfat membentuk kompleks anion, yaitu $\mathrm{UO}_{2}\left(\mathrm{SO}_{4}\right)_{3}{ }^{4-}$ atau $\mathrm{UO}_{2}\left(\mathrm{SO}_{4}\right)_{3}{ }^{2-}$, dan $\mathrm{Th}\left(\mathrm{SO}_{4}\right)_{3}{ }^{2-}$. Uranil sulfat terekstrak sangat baik dengan jenis amina tersier dibandingkan dengan torium sulfat. 
Torium sulfat lebih baik diekstrak dengan jenis amina primer. Koefisien distribusi $(\mathrm{Kd})$ unsur dalam amina tersier adalah uranium 140 , torium $<0,03$. Berdasarkan nilai $\mathrm{Kd}$ ini, diketahui bahwa nilai Kd $\mathrm{U}$ memiliki perbedaan cukup jauh daripada $\mathrm{Kd} T \mathrm{Th}$ sehingga amina tersier cukup selektif terhadap uranium [19]. Kondisi optimum ekstraksi pada variasi konsentrasi TOA adalah 4\% karena pada konsentrasi ini, uranium yang terektrak sudah cukup banyak akan tetapi torium yang terekstrak masih $\leq$ $1,1 \%$.

Konsentrasi uranium yang terekstrak masih belum optimal, hanya 62-66\%. Oleh sebab itu diperlukan variasi proses lainnya seperti perbandingan fase aqueous dan organik (A/O). Pengaruh perbandingan A/O diamati berdasarkan jumlah uranium dan torium yang berada pada larutan aqueous yang dianalisis dengan ICP-OES dan Spektrofotometer UV-Vis dibandingkan dengan kadar uranium dan torium sebelum dilakukan proses ekstraksi. Persen jumlah uranium dan torium yang terekstrak pada larutan organik terlihat pada Gambar 3.

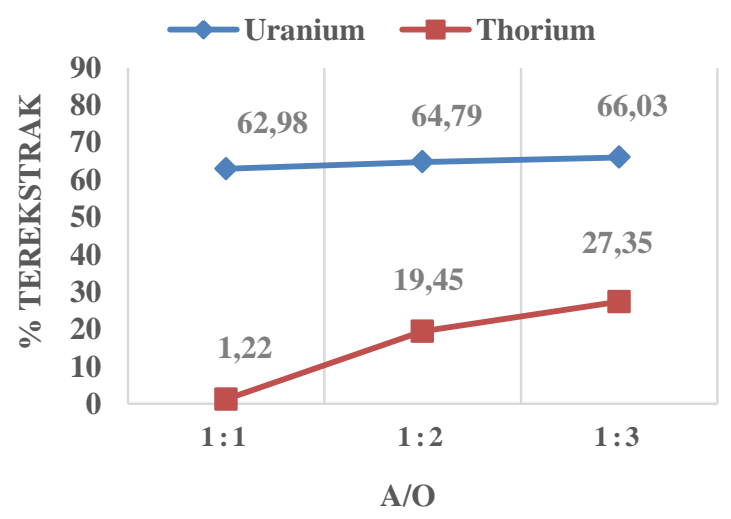

Gambar 3. Pengaruh perbandingan A/O terhadap kadar uranium dan torium.

Jumlah uranium yang terekstrak pada berbagai variasi perbandingan $\mathrm{A} / \mathrm{O}$ memiliki nilai meningkat dengan bertambahnya perbandingan A/O. Semakin banyak larutan organik atau larutan pengekstrak yang digunakan, maka semakin banyak uranium yang terekstrak ke dalam fase organik. Hal ini disebabkan oleh keberadaan fase organik yang lebih banyak, sehingga jumlah uranium yang terikat ke dalam fase organik akan semakin banyak pula [20]. Kondisi optimum ekstraksi pada variasi perbandingan $\mathrm{A} / \mathrm{O}$ adalah 1:1 karena torium yang ikut terekstrak sangat kecil.

Faktor lain yang berpengaruh pada proses ekstraksi adalah waktu pencampuran larutan aqueous yang mengandung uranium dan torium sulfat dengan larutan organik (TOA). Waktu pencampuran ini akan mempengaruhi kecepatan tercapainya kesetimbangan [15]. Pengaruh waktu pencampuran diamati berdasarkan jumlah uranium dan torium yang terekstrak pada berbagai variasi waktu. Persen ekstraksi uranium dan torium pada berbagai variasi waktu terlihat pada Gambar 4.

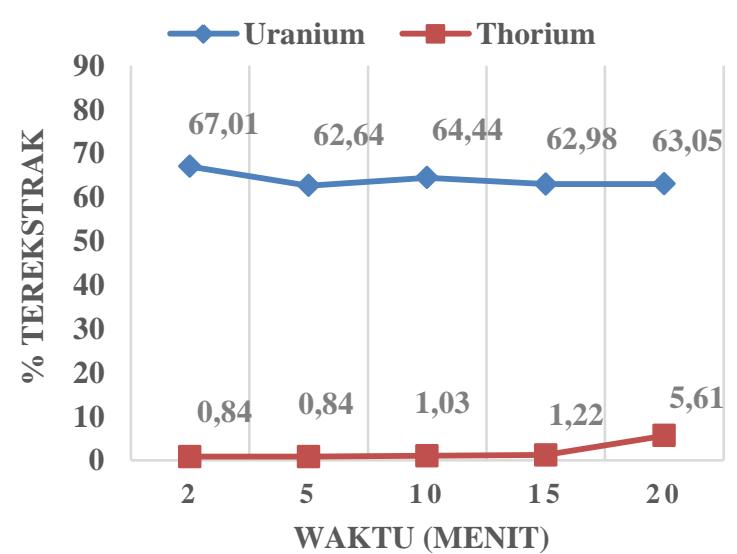

Gambar 4. Pengaruh waktu pencampuran terhadap kadar uranium dan torium.

Dari Gambar 4 terlihat bahwa semakin lama waktu pengadukan yang digunakan, maka semakin sedikit uranium yang terekstrak ke dalam fase organik. Jumlah U yang terekstrak ke dalam larutan organik pada waktu pengadukan $2,5,10,15$, dan 20 menit secara 
berurutan yaitu $67,01 \%, 62,64 \%, 64,44 \%$, $62,98 \%$, dan $63,05 \%$. Waktu pengadukan dari 2-20 menit tidak terlalu berpengaruh signifikan terhadap kadar uranium. Penggunaan waktu pengadukan selama 2 menit dinilai cukup baik karena dapat mengekstrak uranium hingga 67\%. Pengaruh waktu pada kadar torium menunjukkan fenomena yang berlawanan dengan uranium, dimana semakin lama waktu pengadukan yang digunakan maka semakin banyak pula torium yang terekstrak. Peningkatan persen terekstrak torium yang terjadi cukup signifikan pada penggunaan waktu pengadukan lebih dari 15 menit.

Pada penggunaan waktu pengadukan 5 menit hingga 15 menit, jumlah torium yang terekstrak berkisar antara $0,84 \%$ hingga $1,2 \%$. sementara pada penggunaan waktu pengadukan 20 menit jumlah torium yang terekstak ke dalam larutan organik mencapai $5,61 \%$. Hal ini mengakibatkan pemisahan uranium dan torium tidak cukup efektif pada penggunaan konsentrasi waktu pengadukan lebih dari 2 menit. Untuk itu, proses pemisahan uranium dan torium efektif terjadi untuk penggunaan waktu pengadukan 2 menit, dimana uranium yang diekstrak mencapai $67 \%$ sedangkan torium berada dalam jumlah yang relatif kecil yaitu $0,84 \%$.

\section{KESIMPULAN}

Pemisahan uranium dan torium dalam terak timah hasil roasting $\mathrm{NaOH}$ dan leaching $\mathrm{H}_{2} \mathrm{SO}_{4}$ dapat dipisahkan melalui metode ekstraksi dengan trioctylamine (TOA). Kondisi optimum pada penelitian ini diperoleh konsentrasi TOA 4\%, perbandingan A/O 1:1, dan waktu pencampuran aqueous dan organik selama 2 menit. Pada kondisi ini uranium mampu diekstrak sebanyak $67 \%$ dan torium sebanyak $0,84 \%$.

\section{UCAPAN TERIMA KASIH}

Penulis mengucapkan terima kasih kepada pihak yang telah mendukung dan membantu pada penelitian ini. PT Timah atas support bahan baku berupa terak timah dan Kepala Pusat Teknologi Bahan Galian Nuklir (PTBGN) serta teman-teman di Bidang Teknologi Penambangan dan Pengolahan (TPP).

\section{DAFTAR PUSTAKA}

[1] O. Firdaus, "Penggunaan Limbah Peleburan Timah (Tin Slag) Sebagai Agregat Kasar Pada Campuran Hot Rolled Sheet- Wearing Course Untuk Perkerasan Jalan Raya," FROPIL (Forum Prof. Tek. Sipil), vol. 2, no. 2, pp. 120-134, 2014.

[2] Y. Zhou, X. Tong, S. Song, Z. Deng, X. Wang, $\mathrm{X}$. Xie, and F. Xie, "Beneficiation of Cassiterite and Iron Minerals From a Tin Tailing with Magnetizing Roasting-Magnetic Separation Process," Sep. Sci. Technol., vol. 48, no. 9, pp. 1426-1432, 2013.

[3] Z. Su, Y. Zhang, B. Liu, M. Lu, G. Li, and T. Jiang, "Extraction and Separation of Tin from Tin-Bearing Secondary Resources: A Review," $J$. Miner. Met. Mater. Soc., vol. 69, no. 11, pp. 2364-2372, 2017.

[4] A. R. Chakhmouradian and F. Wall, "Rare Earth Elements: Minerals, Mines, Magnets (and More)," Elements, vol. 8, no. 5, pp. 333-340, 2012.

[5] A. Jordens, Y. P. Cheng, and K. E. Waters, "A Review of the Beneficiation of Rare Earth Element Bearing Minerals," Miner. Eng., vol. 41, pp. 97-114, 2013.

[6] G. Tyler, "Rare Earth Elements in Soil and Plant Systems - A Review," Plant Soil, vol. 267, pp. 191-206, 2004.

[7] M. Anggraini and K. M. Irmina, "Pemisahan Unsur Radioaktif dan Logam Tanah Jarang dalam Terak Timah dengan Fusi Alkali dan Pelindian Asam," in Prosiding Seminar Nasional Kebumian XII, 2016, pp. 4-5.

[8] X. Du and T. E. Graedel, "Global Rare Earth InUse Stocks in NdFeB Permanent Magnets," $J$. Ind. Ecol., vol. 15, no. 6, pp. 836-843, 2011.

[9] A. Hastir, N. Kohli, and R. C. Singh, "Comparative Study on Gas Sensing Properties of Rare Earth (Tb, Dy and Er) Doped ZnO Sensor," J. Phys. Chem. Solids, vol. 105, no. February, pp. 23-34, 2017.

[10] E. Dewita, J. K. Barat, and M. Prapatan, "Analisis Potensi Thorium sebagai Bahan Bakar Nuklir Alternatif," J. Pengemb. Energi Nukl., vol. 14, no. Juni, pp. 45-56, 2012. 
[11] S. Chirikure, R. B. Heimann, and D. Killick, "The Technology of Tin Smelting in the Rooiberg Valley, Limpopo Province, South Africa, ca. 1650-1850 CE," J. Archaeol. Sci., vol. 37, no. 7, pp. 1656-1669, 2010.

[12] I. Gaballah, E. Allain, M.-C. Meyer-Joly, and K. Malau, "A Possible Method for the Characterization of Amorphous Slags Recovery of Refractory Metal Oxides from Tin Slags," Metall. Mater. Trans. B, vol. 23, no. 3, pp. 249259, 1992.

[13] B. Briliant, M. Z. Mubarok, K. Trinopiawan, and R. Prassanti, "Studi Pemisahan Thorium dari Besi dan Logam Tanah Jarang dalam Larutan Asam Nitrat dengan Ekstraksi Pelarut Menggunakan Ekstraktan Trioctylphosphine Oxide," Eksplorium, vol. 38, no. 2, p. 133, 2018.

[14] R. Ferliana, B. Wasito, and R. Prassanti, "Ekstraksi Dan Stripping Torium Dari Rafinat Hasil Ekstraksi Uranium Monasit Bangka," J. Forum Nukl., vol. 10, no. 1, pp. 26-37, 2016.

[15] I. Wibawa and D. Sukma, "Ekstraksi Cair-Cair," 2014.

[16] C. B. Boss and K. J. Fredeen, Concepts, Instrumentation, and Techniques in Inductively Couple Plasma Optical Emission Spectrometry,
Third edit. Perkin Elmer, 2004.

[17] M. Anggraini, S. Waluyo, and Rusydi, "Penentuan Jenis Pelarut Pada Pemisahan Uranium dan Thorium dari Slag II," in Prosiding Pertemuan dan Presentasi Ilmiah Fungsional Pengembangab Teknoligi Nuklir VII, 2012, pp. 141-147.

[18] W. J. McDowell and C. F. Coleman, "Interface Mechanism For Uranium Extraction by Amine Sulphate," J. Inorg. Nucl. Chem., vol. 29, no. 5, pp. 1325-1343, 1967.

[19] N. Anis Kundari, R. Prasanti, and Gizella, "Ekstraksi dan Stripping Uranium Hasil Pelarutan Total Monasit Bangka," J. forum Nukl., vol. 1, pp. 12-25, 2016.

[20] K. Trinopiawan, R. Prassanti, Sumarni, and R. Pudjianto, "Pemisahan U dari Th Pada Monasit dengan Metode Ekstraksi Pelarut Alamine," in Prosiding Seminar Geologi Nuklir dan Sumber Daya Tambang, 2012, pp. 287-295. 